\title{
Knowledge Sharing between Beauty Industry Workers Based on General Individual and Organizational Characteristics
}

\author{
Jung-Eun Park ${ }^{1}$, Byung-Un Jin ${ }^{2}$, Eun-Jun Park ${ }^{1 *}$ \\ ${ }^{1}$ Department of Hair and Makeup Design, Seokyeong University, Seoul, Korea \\ ${ }^{2}$ Design \& Art Institute, Hansung University, Seoul, Korea
}

\author{
"Corresponding author: Eun-Jun Park, \\ Department of Hair and Makeup Design, \\ Seokyeong University, 124 Seogyeong-ro, \\ Seongbuk-gu, Seoul 02713, Korea \\ Tel.: +82 29407846 \\ Fax: +82 29407846 \\ Email: ayamdream@hanmail.net
}

Received February 06, 2020

Revised March 08, 2020

Accepted March 20, 2020

Published March 30, 2020

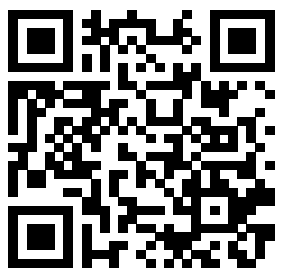

\begin{abstract}
Purpose: To establish an understanding of effective knowledge sharing that occurs between service works in the beauty industry according to individual organizational characteristics. Methods: Data were collected from individuals working in the beauty service industry and analyzed using Statistical Package for the Social Sciences (SPSS) 22.0. Data analysis methods included frequency analysis, factor analysis, reliability analysis, independent sample $t$-test, and one-way analysis of variance. Results: The analysis revealed that there were significant differences in knowledge sharing depending on gender, age, marital status, educational background, position, salary type, work experience, organization type, number of employees in the organization, and professional field. Conclusion: The basic data drawn from this study could be used in the development of the beauty industry, by providing of how with an of how knowledge-sharing can occur between works and be beneficial for their organization and the industry as a whole.
\end{abstract}

Keywords: Beauty, Beauty industry, Beauty industry workers, Knowledge sharing, General characteristics

\section{Introduction}

오늘날 급변하는 환경과 기업들간의 치열한 경쟁 속에서 미용서비 스업은 다른 산업에 비해 인적자원의 의존도가 높은 서비스업이라고 할 수 있다(Kim \& Lee, 2018). 미용서비스업의 종사자는 전문적인 분야로 지식과 기술, 정보의 증가에 맞춰 고객에게 미적 만족을 주는 업무를 수행하며(Min et al., 2013), 기업에서는 종사자의 서비스 교 육 및 훈련에 많은 시간과 투자를 필요로 한다(Lee et al., 2012). 기 업은 조직의 역량을 강화하기 위하여 지식을 확산하고 공유하려는 노력을 하고 있으며, 자신이 알고 있는 유용한 경험이나 노하우 등 기타 지식을 다른 사람에게 전달하고 동시에 타인의 것을 제공받는 역동적인 상호작용을 통하여 지식창출은 보다 효과적으로 일어날 수 있다(Nonaka, 1994).

지식공유란 조직이 보유한 지식자산을 종사자들에게 공유시킴 으로 지식의 활용을 극대화하고, 조직역량을 강화하는 활동이다 (Grant, 1996). 지식을 얼마나 효과적으로 업무에 활용하느냐에 따
라 조직의 경쟁력은 높아질 수 있다.

지식공유와 관련된 선행 연구를 살펴보면 Lee \& Cha (2006)은 중 앙행정기관을 대상으로 지식공유 영향요인을 분석하고 지식공유가 업무성과에 미치는 영향을 분석하여 지식공유가 업무성과에 긍정적 인 영향을 미치는 것을 밝혔으며, Seol (2014)는 변혁적 리더십과 지 식공유의 관계에 있어서 사회적 자본의 매개효과를 연구하여 변혁 적 리더십과 사회적 자본은 지식공유에 긍정적인 영향을 미치는 것 을 확인하였다. Jeon \& Hong (2019)은 중소기업의 지식공유 활동이 기업성과에 미치는 영향을 분석하였으며, Bae \& Baek (2016)은 개 인의 네트워크 위치가 지식공유 의도에 미치는 영향을 분석하여 네 트워크 내에서의 관계를 통하여 자연적으로 형성되어진 위치는 개별 구성원들의 지식공유 의도에 영향을 미치는 것을 실증적으로 확인 하였다. 이처럼 지식공유에 관한 많은 연구들이 선행되어왔지만 미 용서비스업 종사자의 특성을 고려한 지식공유의 연구는 아직 미비한 실정이다.

이에 본 연구는 미용서비스업 종사자의 특성에 따른 지식공유의 
Effective knowledge sharing in the beauty industry

차이를 알아보고 향후 미용서비스업에서의 효과적인 지식공유의 방 향을 제시하는데 목적이 있다.

Table 1. General characteristics of participants

$(\mathbf{N}=\mathbf{7 0 0}, \%)$

\begin{tabular}{|c|c|c|c|}
\hline \multirow{2}{*}{ Items } & & \multicolumn{2}{|c|}{ Total } \\
\hline & & Frequency $(\mathrm{N})$ & Percentage (\%) \\
\hline \multirow{2}{*}{ Gender } & Men & 84 & 12.0 \\
\hline & Women & 616 & 88.0 \\
\hline \multirow{5}{*}{ Age } & Teenager & 12 & 1.7 \\
\hline & $20 \mathrm{~s}$ & 535 & 76.4 \\
\hline & $30 \mathrm{~s}$ & 101 & 14.4 \\
\hline & $40 \mathrm{~s}$ & 43 & 6.1 \\
\hline & 50 s or older & 9 & 1.3 \\
\hline \multirow{3}{*}{ Marital status } & Single & 599 & 85.6 \\
\hline & Married & 93 & 13.2 \\
\hline & Divorced & 8 & 1.1 \\
\hline \multirow{4}{*}{ Education level } & Graduated from high school & 103 & 14.7 \\
\hline & Currently attending or graduated from college & 185 & 26.4 \\
\hline & Currently attending or graduated from university & 356 & 50.9 \\
\hline & Currently attending or graduated from graduate school & 56 & 8.0 \\
\hline \multirow{5}{*}{ Position } & Intern (assistant) & 337 & 48.1 \\
\hline & Designer (working-level) & 237 & 33.9 \\
\hline & Director (branch representative) & 50 & 7.1 \\
\hline & Chairman (representative) & 48 & 6.9 \\
\hline & Manager & 28 & 4.0 \\
\hline \multirow{3}{*}{ Wage type } & Wage & 480 & 68.6 \\
\hline & Incentive & 169 & 24.1 \\
\hline & Others & 51 & 7.3 \\
\hline \multirow{5}{*}{ Years of experience } & 3 years or less & 431 & 61.6 \\
\hline & $4-6$ years & 121 & 17.3 \\
\hline & $7-9$ years & 67 & 9.6 \\
\hline & $10-12$ years & 33 & 4.7 \\
\hline & 13 years or more & 48 & 6.9 \\
\hline \multirow{3}{*}{ Type of organization } & Franchise & 404 & 57.7 \\
\hline & Private enterprise & 269 & 38.4 \\
\hline & Other & 27 & 3.9 \\
\hline \multirow{5}{*}{ Number of employees } & 5 persons or less & 184 & 26.3 \\
\hline & $6-10$ persons & 241 & 34.4 \\
\hline & $11-15$ persons & 160 & 22.9 \\
\hline & $16-20$ persons & 49 & 7.0 \\
\hline & 21 persons or more & 66 & 9.4 \\
\hline \multirow{5}{*}{ Beauty field } & Hair & 504 & 72.0 \\
\hline & Makeup & 24 & 3.4 \\
\hline & Skin care & 122 & 17.4 \\
\hline & Nail art & 28 & 4.0 \\
\hline & Other & 22 & 3.1 \\
\hline Total & & 700 & 100.0 \\
\hline
\end{tabular}




\section{Theoretical Background}

\section{1. 지식공유}

다양한 집단의 주장과 견해를 습득하고 이를 통해 상생하는 길을 찾아야 하는 시대이다(Choi \& Chung, 2018). 지식공유는 지식경 영의 짧은 역사에도 불구하고 선구적 기업을 중심으로 조식 전체적 인 측면의 성과향상에 영향을 미치고 있다(Song, 2019). 지식공유 를 통해 조직 내 분산되어 있는 개인지식이나 소집단에 의해 보유된 지식이 조직 내에 확산되어 새로운 조직지식과 조직역량이 창출될 수 있다는 것을 의미한다(Kim, 2011). 지식공유의 구성요소에 대한 선행연구를 살펴보면 Chung (2006)은 지식공유의 선행요인과 지식 공유가 혁신행동에 미치는 영향에 대한 연구에서 지식공유의 구성 요소를 실제 혁신행동에 영향을 미칠 수 있는 구조적 요인과 관계적 요인으로 구분하여 측정하였고, Kang (2005)은 지식공유 영향요인 이 업무성과에 미치는 영향에서 지식공유의 구성요소를 조직적 요 인, 개인적 요인, 지식특성 요인으로 구분하여 측정하였다. 이에 본
연구에서 적합한 요인으로 선행연구를 수정, 보완하여 지식저장, 구 조적공유, 관계적공유, 개인적공유로 하위요인을 구성하였다.

\section{Methods}

\section{1. 연구문제}

본 연구의 연구문제는 다음과 같이 설정되었다.

첫째, 조사대상의 일반적 특성을 알아본다.

둘째, 지식공유의 타당도 및 신뢰도를 알아본다.

셋째, 미용서비스업 종사자의 특성에 따른 지식공유의 차이를 알 아본다.

\section{2. 연구대상 및 자료수집}

본 연구의 조사대상은 미용종사자를 대상으로 설정하였다. 2016년 5월 4일부터 2016년 6월 20일까지 실시되었고 총 730부

Table 2. Dimensions of knowledge sharing

\begin{tabular}{|c|c|c|c|c|}
\hline & Factor 1 & Factor 2 & Factor 3 & Factor 4 \\
\hline Questions related to Knowledge sharing & $\begin{array}{l}\text { Knowledge } \\
\text { storing }\end{array}$ & $\begin{array}{l}\text { Structuring } \\
\text { sharing }\end{array}$ & $\begin{array}{l}\text { Relational } \\
\text { sharing }\end{array}$ & $\begin{array}{l}\text { Personal } \\
\text { sharing }\end{array}$ \\
\hline I seek opinions or create materials/data relating to the knowledge I use & 0.805 & 0.189 & 0.263 & 0.196 \\
\hline I classify acquired knowledge systematically. & 0.792 & 0.183 & 0.219 & 0.151 \\
\hline I document my know-how, failures, problem-solving procedures, etc. & 0.792 & 0.249 & 0.067 & 0.184 \\
\hline I update my knowledge constantly. & 0.780 & 0.193 & 0.174 & 0.213 \\
\hline $\begin{array}{l}\text { Employees in my organization tend to be satisfied with the processe of } \\
\text { evaluation and associated reward/compensation. }\end{array}$ & 0.215 & 0.810 & 0.319 & 0.156 \\
\hline $\begin{array}{l}\text { My organization creates a learning environment to expand learning of } \\
\text { content service. }\end{array}$ & 0.245 & 0.801 & 0.188 & 0.195 \\
\hline $\begin{array}{l}\text { Employees of my organization are given proper compensation/reward for } \\
\text { their achievements, efforts, and level of responsibility. }\end{array}$ & 0.262 & 0.735 & 0.296 & 0.172 \\
\hline $\begin{array}{l}\text { My company tends to give constant support and advise to facilitate } \\
\text { active knowledge sharing }\end{array}$ & 0.194 & 0.729 & 0.317 & 0.259 \\
\hline $\begin{array}{l}\text { My organization usually makes effort to help maintain interpersonal } \\
\text { relationship among colleagues. }\end{array}$ & 0.178 & 0.263 & 0.833 & 0.218 \\
\hline $\begin{array}{l}\text { In my organization, colleagues have a good understanding of work- } \\
\text { related discussion. }\end{array}$ & 0.200 & 0.229 & 0.819 & 0.150 \\
\hline In my organization, trust among superiors/colleagues tends to be strong. & 0.181 & 0.339 & 0.723 & 0.240 \\
\hline In my organization, colleagues are very active in knowledge sharing. & 0.228 & 0.295 & 0.666 & 0.308 \\
\hline $\begin{array}{l}\text { I share knowledge that I acquire from business travel or education/ } \\
\text { training, etc., with my colleague }\end{array}$ & 0.217 & 0.206 & 0.212 & 0.859 \\
\hline $\begin{array}{l}\text { I share work-related knowledge that I have acquired individually with } \\
\text { colleague }\end{array}$ & 0.261 & 0.235 & 0.228 & 0.802 \\
\hline $\begin{array}{l}\text { I share materials, manuals, documents, etc., which are helpful for } \\
\text { improving work performance with colleagues }\end{array}$ & 0.203 & 0.180 & 0.256 & 0.798 \\
\hline Unique value & 3.034 & 2.992 & 2.969 & 2.538 \\
\hline Explained variance (\%) & 20.228 & 19.948 & 19.794 & 16.918 \\
\hline Cumulative variance (\%) & 20.228 & 40.176 & 59.970 & 76.889 \\
\hline Reliability coefficient (Cronbach's $\alpha$ ) & 0.878 & 0.894 & 0.889 & 0.891 \\
\hline
\end{tabular}


Effective knowledge sharing in the beauty industry

의 설문지를 배포하여 700 부가 최종 분석 자료로 사용되었다.

\section{3. 측정도구}

본 연구를 위한 설문지는 일반적 특성 10 문항, 지식공유 15 문항 으로 구성하였다. 각 문항은 1점 '전혀 그렇지 않다', 5 점 '매우 그렇 다'로 5 점 리커트 척도로 측정하였다.

\section{4. 자료처리 및 분석방법}

수집된 자료를 분석하기 위해 Statistical Package for the Social Sciences (SPSS ver 22.0; IBM, USA)이 사용되었고, 자료 분석 방법은 다음과 같다.

첫째, 조사대상의 일반적 특성을 알아보기 위해 빈도분석이 사용 되었다.

Table 3. Differences in knowledge sharing by gender

\begin{tabular}{|c|c|c|c|c|c|}
\hline Gender & & & $M$ & S.D. & $t$-value $(p)$ \\
\hline \multirow{8}{*}{ Knowledge sharing } & \multirow{2}{*}{ Knowledge storing } & Men & 3.46 & 0.864 & \multirow{2}{*}{1.624} \\
\hline & & Women & 3.33 & 0.757 & \\
\hline & \multirow{2}{*}{ Structuring sharing } & Men & 3.65 & 0.763 & \multirow{2}{*}{$3.299^{*}$} \\
\hline & & Women & 3.42 & 0.796 & \\
\hline & \multirow{2}{*}{ Relational sharing } & Men & 3.71 & 0.773 & \multirow{2}{*}{1.585} \\
\hline & & Women & 3.55 & 0.770 & \\
\hline & \multirow{2}{*}{ Personal sharing } & Men & 3.91 & 0.840 & \multirow{2}{*}{1.846} \\
\hline & & Women & 3.66 & 0.808 & \\
\hline
\end{tabular}

${ }^{* *} p<0.01 ; \mathrm{M}$, mean; S.D,. standard deviation.

Table 4. Differences in knowledge sharing by age

\begin{tabular}{|c|c|c|c|c|c|}
\hline & Age & & $M$ & S.D. & $t$-value $(p)$ \\
\hline \multirow{24}{*}{ Knowledge sharing } & \multirow{6}{*}{ Knowledge storing } & Teenager & $3.31 \mathrm{~B}$ & 0.513 & \multirow{6}{*}{$15.593^{* * *}$} \\
\hline & & $20 s$ & $3.23 \mathrm{~B}$ & 0.752 & \\
\hline & & $30 s$ & $3.66 \mathrm{AB}$ & 0.755 & \\
\hline & & $40 \mathrm{~s}$ & $3.95 \mathrm{~A}$ & 0.623 & \\
\hline & & 50 s or older & 3.67AB & 0.573 & \\
\hline & & Total & 3.34 & 0.771 & \\
\hline & \multirow{6}{*}{ Structuring sharing } & Teenager & $3.44 \mathrm{~B}$ & 0.930 & \multirow{6}{*}{$12.637^{* * *}$} \\
\hline & & $20 s$ & $3.34 \mathrm{~B}$ & 0.777 & \\
\hline & & $30 \mathrm{~s}$ & $3.78 \mathrm{AB}$ & 0.763 & \\
\hline & & $40 s$ & $3.97 \mathrm{~A}$ & 0.671 & \\
\hline & & 50 s or older & $3.72 \mathrm{AB}$ & 0.631 & \\
\hline & & Total & 3.45 & 0.795 & \\
\hline & \multirow{6}{*}{ Relational sharing } & Teenager & $3.83 A B$ & 0.710 & \multirow{6}{*}{$14.202^{* * *}$} \\
\hline & & $20 \mathrm{~s}$ & $3.46 \mathrm{~B}$ & 0.754 & \\
\hline & & $30 \mathrm{~s}$ & $3.89 A B$ & 0.716 & \\
\hline & & $40 s$ & $4.10 \mathrm{~A}$ & 0.693 & \\
\hline & & 50 s or older & $3.94 \mathrm{~A}$ & 0.726 & \\
\hline & & Total & 3.57 & 0.772 & \\
\hline & \multirow{6}{*}{ Personal sharing } & Teenager & $3.89 A B$ & 0.687 & \multirow{6}{*}{$9.091^{\text {** }}$} \\
\hline & & $20 s$ & $3.59 \mathrm{~B}$ & 0.815 & \\
\hline & & $30 \mathrm{~s}$ & 4.00AB & 0.749 & \\
\hline & & $40 s$ & $4.05 \mathrm{AB}$ & 0.704 & \\
\hline & & 50 s or older & $4.15 \mathrm{~A}$ & 0.784 & \\
\hline & & Total & 3.69 & 0.815 & \\
\hline
\end{tabular}

${ }^{* * *} p<0.001$; Duncan test results are A>B; M, mean; S.D,. standard deviation. 
둘째, 지식공유의 타당도 및 신뢰도를 알아보기 위해 요인분석, 신뢰도분석이 사용되었다.

셋째, 미용서비스업 종사자의 특성에 따른 지식공유의 차이를 알 아보기 위해 독립표본 $t$-test, 일원변량분석(One way ANOVA)이 사용되었다.

\section{Results and Discussion}

\section{1. 조사대상의 일반적 특성}

조사대상인 미용서비스업 종사자의 일반적 특성을 알아보기 위 해 빈도분석을 실시한 결과는 Table 1 과 같다.

성별은 남자 $12.0 \%$, 여자 $88.0 \%$ 로 여자가 높게 나타났고 연령 은 10 대 $1.7 \%, 20$ 대 $76.4 \%, 30$ 대 $14.4 \%, 40$ 대 $6.1 \%, 50$ 대 이상 $1.3 \%$ 로 20 대가 가장 높게 나타났다. 결혼여부의 경우 미혼 $85.6 \%$, 기혼 $13.2 \%$, 이혼 $1.1 \%$ 로 미혼이 가장 높게 나타났다. 학력을 알아 본 결과 고등학교 졸업 $14.7 \%$, 전문대학 재학/졸업 $26.4 \%$, 대학교 재학/졸업 $50.9 \%$, 대학원 재학/졸업 $8.0 \%$ 로 대학교 재학/졸업이 가장 높게 나타났다. 직급은 인턴(어시스트) $48.1 \%$, 디자이너(실무 자) $33.9 \%$, 실장(점장) $7.1 \%$, 원장(대표) $6.9 \%$, 매니저 $4.0 \%$ 로 인 턴(어시스트)가 가장 높게 나타났다. 급여형태를 알아본 결과 급여 $68.6 \%$, 인센티브 $24.1 \%$, 기타 $7.3 \%$ 로 급여가 가장 높게 나타났다. 미용경력은 3년이하 $61.6 \%, 4-6$ 년 17.3\%, 7-9년 9.6\%, 10-12 년 $4.7 \%, 13$ 년 이상 $6.9 \%$ 로 3 년 이하가 가장 높게 나타났다. 회 사형태로는 프랜차이즈 $57.7 \%, 6-10$ 명 $34.4 \%, 11-15$ 명 $22.9 \%$,
16-20명 7.0\%, 21명이상 9.4\%로 6-10명이 가장 높게 나타났다. 미용분야를 알아본 결과 헤어 $72.0 \%$, 메이크업 $3.4 \%$, 피부관리 $17 . \%$, 네일아트 $4.0 \%$, 기타 $3.1 \%$ 로 헤어가 가장 높게 나타났다.

\section{2. 지식공유의 타당성 및 신뢰도}

지식공유 문항에 대해 요인분석을 이용한 타당성 검증결과 Table 2 와 같이 네 개의 요인이 도출되었다. Bartlett의 단위행렬 점검 결과 $\mathrm{x}^{2}=7407.011(\mathrm{df}=105, \mathrm{Sig}=0.000), \mathrm{KMO}$ 값 0.921으로 나타났으며, 공통성은 0.677 이상으로 나타났다.

첫 번째 요인은 '지식저장' 요인으로 요인적재값은 0.780-0.805 로 나타났으며, 고유값은 3.034 , 분산설명비율은 $20.2 \%$ 로 나타났 다. 두 번째 요인은 '구조적공유' 요인으로 요인적재값은 0.7290.810 으로 나타났으며, 고유값은 2.992 , 분산설명비율은 $19.9 \%$ 로 나타났다. 세 번째 요인은 '관계적공유' 요인으로 요인적재값은 0.666-0.833으로 나타났으며, 고유값은 2.969, 분산설명비율은 $19.7 \%$ 로 나타났다. 네 번째 요인은 '개인적공유' 요인으로 요인적 재값은 0.798-0.859으로 나타났으며, 고유값은 2.538 , 분산설명 비율은 $16.9 \%$ 로 나타났다.

요인분석 결과 도출된 네 개의 요인이 전체 분산의 $76.8 \%$ 이상 설명되고 있는 것으로 나타났다.

지식공유에 대한 신뢰성 검증 결과, 신뢰도 계수인 Cronbach's $\alpha$ 는 0.878-0.894로 높게 나타나, 신뢰성에는 문제가 없는 것으로 나타났다. 요인별로 살펴보면, 지식저장 0.878 , 구조적공유 0.894 , 관계적공유 0.889 , 개인적공유 0.891 로 나타났다.

Table 5. Differences in knowledge sharing according to marital status

\begin{tabular}{|c|c|c|c|c|c|}
\hline & Marital status & & $M$ & S.D. & $t$-value $(p)$ \\
\hline \multirow{16}{*}{ Knowledge sharing } & \multirow{4}{*}{ Knowledge storing } & Single & $3.26 \mathrm{~B}$ & 0.750 & \multirow{4}{*}{$25.354^{* * *}$} \\
\hline & & Married & $3.85 \mathrm{~A}$ & 0.719 & \\
\hline & & Divorced & 3.64AB & 0.708 & \\
\hline & & Total & 3.34 & 0.771 & \\
\hline & \multirow{4}{*}{ Structuring sharing } & Single & 3.37B & 0.785 & \multirow{4}{*}{$18.737^{* * *}$} \\
\hline & & Married & $3.89 \mathrm{~A}$ & 0.715 & \\
\hline & & Divorced & $3.78 A B$ & 0.765 & \\
\hline & & Total & 3.45 & 0.795 & \\
\hline & \multirow{4}{*}{ Relational sharing } & Single & $3.51 \mathrm{~B}$ & 0.762 & \multirow{4}{*}{$17.172^{* * *}$} \\
\hline & & Married & $3.93 \mathrm{~B}$ & 0.678 & \\
\hline & & Divorced & $4.33 \mathrm{~A}$ & 1.016 & \\
\hline & & Total & 3.57 & 0.772 & \\
\hline & \multirow{4}{*}{ Personal sharing } & Single & $3.62 B$ & 0.808 & \multirow{4}{*}{$14.569^{* * *}$} \\
\hline & & Married & 4.06AB & 0.731 & \\
\hline & & Divorced & $4.30 \mathrm{~A}$ & 0.904 & \\
\hline & & Total & 3.69 & 0.815 & \\
\hline
\end{tabular}

${ }^{* * *} p<0.001$; Duncan test results are A>B; M, mean; S.D.. standard deviation. 


\section{3. 미용서비스업 종사자의 특성에 따른 지식공유의 차이}

미용서비스업 종사자의 특성(성별, 연령, 결혼여부, 학력, 직급, 급 여형태, 근무경력, 회사형태, 직원 수, 전문분야)에 따른 지식공유 의 차이를 알아보기 위해 독립표본 $t$-test, 일원변량분석(one way $\mathrm{ANOVA)}$ 을 실시한 결과는 다음과 같다. 사후검증은 던컨테스트를 사 용하였다.

1) 성별에 따른 지식공유의 차이

구조적공유 요인에서 Table 3 과 같이 통계적으로 유의미한 차이를 보였고( $p<0.01)$, 남자의 평균이 여자보다 높게 나타났다.

\section{2) 연령에 따른 지식공유의 차이}

지식저장, 구조적공유, 관계적공유, 개인적공유 요인에서 Table 4와 같이 통계적으로 유의미한 차이를 보였다 $(p<0.001)$. 지식저장, 구조적 공유, 관계적공유는 40 대의 평균이 가장 높았고 20 대의 평균이 가장
낮게 나타났다. 개인적공유는 50 대의 평균이 20대의 평균에 비해 상대 적으로 높게 나타났다. 이는 어느 정도의 연령이 높아야 보유한 지식 의 정도가 많아지고 이를 활용하고 역할을 수행하는 업무능력이 뛰어 난 것이라 사료된다. 이러한 결과는 $\mathrm{Kim} \& \mathrm{Kim}$ (2000)의 지식경영의 성공요인에 관한 연구에서 지식을 활용하는 능력, 지식을 검색하고 공 유하는 능력, 지식을 창조하는 능력 등이 지식공유활동을 높이는 것에 영향을 미치는 것으로 나타났으며, 본 연구와 유사한 결과를 보였다.

3) 결혼여부에 따른 지식공유의 차이

지식저장, 구조적공유, 관계적공유, 개인적공유 요인에서 Table 5 와 같이 통계적으로 유의미한 차이를 보였다( $p<0.001)$. 지식저장, 구조적 공유는 기혼의 평균이 미혼의 평균에 비해 상대적으로 높게 나타났고, 관계적공유, 개인적공유는 이혼의 평균이 미혼의 평균에 비해 상대적 으로 높게 나타났다.

\section{Table 6. Differences in knowledge sharing by educational level}

\begin{tabular}{|c|c|c|c|c|c|}
\hline & Education level & & $M$ & S.D. & $t$-value $(p)$ \\
\hline \multirow{20}{*}{ Knowledge sharing } & \multirow{5}{*}{ Knowledge storing } & Graduated from high school & 3.53B & 0.939 & \multirow{5}{*}{$13.392^{* * *}$} \\
\hline & & $\begin{array}{l}\text { Currently attending or graduated } \\
\text { from college }\end{array}$ & $3.42 B$ & 0.767 & \\
\hline & & $\begin{array}{l}\text { Currently attending or graduated } \\
\text { from university }\end{array}$ & $3.19 \mathrm{C}$ & 0.677 & \\
\hline & & $\begin{array}{l}\text { Currently attending or graduated } \\
\text { from graduate school }\end{array}$ & $3.74 \mathrm{~A}$ & 0.755 & \\
\hline & & Total & 3.34 & 0.771 & \\
\hline & \multirow{5}{*}{ Structuring sharing } & Graduated from high school & $3.70 \mathrm{~A}$ & 0.827 & \multirow{5}{*}{$20.207^{* * *}$} \\
\hline & & $\begin{array}{l}\text { Currently attending or graduated } \\
\text { from college }\end{array}$ & $3.69 B$ & 0.760 & \\
\hline & & $\begin{array}{l}\text { Currently attending or graduated } \\
\text { from university }\end{array}$ & $3.23 \mathrm{~B}$ & 0.739 & \\
\hline & & $\begin{array}{l}\text { Currently attending or graduated } \\
\text { from graduate school }\end{array}$ & $3.56 \mathrm{~A}$ & 0.816 & \\
\hline & & Total & 3.45 & 0.795 & \\
\hline & \multirow{5}{*}{ Relational sharing } & Graduated from high school & $3.89 \mathrm{~A}$ & 0.731 & \multirow{5}{*}{$19.980^{* * *}$} \\
\hline & & $\begin{array}{l}\text { Currently attending or graduated } \\
\text { from college }\end{array}$ & 3.74B & 0.727 & \\
\hline & & $\begin{array}{l}\text { Currently attending or graduated } \\
\text { from university }\end{array}$ & $3.36 \mathrm{~B}$ & 0.746 & \\
\hline & & $\begin{array}{l}\text { Currently attending or graduated } \\
\text { from graduate school }\end{array}$ & $3.76 \mathrm{~A}$ & 0.787 & \\
\hline & & Total & 3.57 & 0.772 & \\
\hline & \multirow{5}{*}{ Personal sharing } & Graduated from high school & $3.89 \mathrm{~A}$ & 0.883 & \multirow{5}{*}{$11.184^{* * *}$} \\
\hline & & $\begin{array}{l}\text { Currently attending or graduated } \\
\text { from college }\end{array}$ & $3.86 \mathrm{~A}$ & 0.796 & \\
\hline & & $\begin{array}{l}\text { Currently attending or graduated } \\
\text { from university }\end{array}$ & $3.52 B$ & 0.744 & \\
\hline & & $\begin{array}{l}\text { Currently attending or graduated } \\
\text { from graduate school }\end{array}$ & $3.85 \mathrm{~A}$ & 0.956 & \\
\hline & & Total & 3.69 & 0.815 & \\
\hline
\end{tabular}

${ }^{* * *} p<0.001$; Duncan test results are $\mathrm{A}>\mathrm{B}>\mathrm{C} ; \mathrm{M}$, mean; S.D,. standard deviation. 
4) 학력에 따른 지식공유의 차이

지식저장, 구조적공유, 관계적공유, 개인적공유 요인에서 Table 6 과 같이 통계적으로 유의미한 차이를 보였다 $(p<0.001)$. 지식저장 은 대학원 재학/졸업의 평균이 가장 높게 나타났고, 구조적공유, 관 계적공유, 개인적공유는 고등학교졸업의 평균이 가장 높게 나타났 다. 이러한 결과는 Kim \& Joh (2004)의 비서직 종사자의 지식공 유에 관한 연구에서 높은 학력이 높아질수록 지식공유가 더 활발히 이루어지는 것으로 나타났으며, 본 연구와 유사한 결과를 보였다.

\section{5) 직급에 따른 지식공유의 차이}

지식저장, 구조적공유, 관계적공유, 개인적공유 요인에서 Table 7 과 같이 통계적으로 유의미한 차이를 보였다 $(p<0.001)$. 지식저장, 구조적공유, 관계적공유, 개인적공유 네 요인 모두 원장(대표)의 평 균이 인턴(어시스트)의 평균에 비해 상대적으로 높게 나타났다. 이 러한 결과는 Lee \& Moon (2018)의 지식공유 및 활용이 현장프로 젝트 성과에 미치는 영향에 관한 연구에서 보상수준이 높을수록 지 식공유 및 활용에 긍정적인 영향을 미치는 것으로 나타났으며, 본
연구와 유사한 결과를 보였다.

6) 급여형태에 따른 지식공유의 차이

지식저장, 구조적공유, 관계적공유, 개인적공유 요인에서 Table 8 과 같이 통계적으로 유의미한 차이를 보였다 $(p<0.001)$. 지식저장, 구조적공유, 관계적공유, 개인적공유 네 요인 모두 기타의 평균이 급여의 평균에 비해 상대적으로 높게 나타났다.

\section{7) 근무경력에 따른 지식공유의 차이}

지식저장, 구조적공유, 관계적공유, 개인적공유 요인에서 Table 9 와 같이 통계적으로 유의미한 차이를 보였다 $(p<0.001)$. 지식저장, 구조적공유, 관계적공유 요인은 13 년 이상의 평균이 가장 높게 나 타났고 3 년 이하의 평균이 가장 낮게 나타났다. 개인적 공유 요인 은 10 년에서 12 년 미만, 13 년 이상의 평균이 동일하게 가장 높게 나타났고 3 년 이하의 평균이 가장 낮게 나타났다. 이는 근무경력이 높을수록 회사에서 관여할 수 있는 부분이 많아지기 때문이라 사료 된다. 이러한 결과는 Cho \& Kang (2017)의 경영참가가 구성원들

\section{Table 7. Differences in knowledge sharing by position}

\begin{tabular}{|c|c|c|c|c|c|}
\hline & Post & & M & S.D. & $F$-value $(p)$ \\
\hline \multirow{24}{*}{ Knowledge sharing } & \multirow{6}{*}{ Knowledge storing } & Intern (assistant) & $3.19 \mathrm{C}$ & 0.762 & \multirow{6}{*}{$18.832^{* * *}$} \\
\hline & & Designer (working- level) & $3.32 \mathrm{AB}$ & 0.716 & \\
\hline & & Director (branch representative) & $3.78 \mathrm{~A}$ & 0.762 & \\
\hline & & Chairman (representative) & $4.02 \mathrm{~A}$ & 0.648 & \\
\hline & & Manager & $3.48 \mathrm{~B}$ & 0.627 & \\
\hline & & Total & 3.34 & 0.771 & \\
\hline & \multirow{6}{*}{ Structuring sharing } & Intern (assistant) & $3.35 \mathrm{C}$ & 0.807 & \multirow{6}{*}{$8.936^{* * *}$} \\
\hline & & Designer (working- level) & $3.40 \mathrm{C}$ & 0.749 & \\
\hline & & Director (branch representative) & $3.79 A B$ & 0.788 & \\
\hline & & Chairman (representative) & $3.94 \mathrm{~A}$ & 0.719 & \\
\hline & & Manager & 3.57BC & 0.742 & \\
\hline & & Total & 3.45 & 0.795 & \\
\hline & \multirow{6}{*}{ Relational sharing } & Intern (assistant) & $3.47 \mathrm{~B}$ & 0.774 & \multirow{6}{*}{$10.255^{* * *}$} \\
\hline & & Designer (working- level) & 3.54B & 0.730 & \\
\hline & & Director (branch representative) & $3.87 \mathrm{~A}$ & 0.760 & \\
\hline & & Chairman (representative) & $4.14 \mathrm{~A}$ & 0.690 & \\
\hline & & Manager & $3.56 \mathrm{~B}$ & 0.760 & \\
\hline & & Total & 3.57 & 0.772 & \\
\hline & \multirow{6}{*}{ Personal sharing } & Intern (assistant) & $3.62 C$ & 0.809 & \multirow{6}{*}{$6.747^{* * *}$} \\
\hline & & Designer (working- level) & $3.63 \mathrm{C}$ & 0.820 & \\
\hline & & Director (branch representative) & $3.96 \mathrm{AB}$ & 0.682 & \\
\hline & & Chairman (representative) & $4.17 \mathrm{~A}$ & 0.787 & \\
\hline & & Manager & 3.71BC & 0.779 & \\
\hline & & Total & 3.69 & 0.815 & \\
\hline
\end{tabular}

${ }^{* * *} p<0.001$; Duncan test results are A>B $>C ; M$, mean; S.D,. standard deviation. 
Effective knowledge sharing in the beauty industry

Table 8. Differences in knowledge sharing by wage type

\begin{tabular}{|c|c|c|c|c|c|}
\hline & Type of wage & & M & S.D. & $F$-value $(p)$ \\
\hline \multirow{16}{*}{ Knowledge sharing } & \multirow{4}{*}{ Knowledge storing } & Wage & $3.20 \mathrm{C}$ & 0.737 & \multirow{4}{*}{$30.991^{\text {** }}$} \\
\hline & & Incentive & $3.57 \mathrm{~B}$ & 0.772 & \\
\hline & & Other & $3.90 \mathrm{~A}$ & 0.646 & \\
\hline & & Total & 3.34 & 0.771 & \\
\hline & \multirow{4}{*}{ Structuring sharing } & Wage & $3.32 \mathrm{~B}$ & 0.785 & \multirow{4}{*}{$23.300^{* * *}$} \\
\hline & & Incentive & $3.69 \mathrm{~A}$ & 0.739 & \\
\hline & & Other & $3.88 \mathrm{~A}$ & 0.744 & \\
\hline & & Total & 3.45 & 0.795 & \\
\hline & \multirow{4}{*}{ Relational sharing } & Wage & $3.45 \mathrm{C}$ & 0.768 & \multirow{4}{*}{$22.214^{* * *}$} \\
\hline & & Incentive & $3.79 \mathrm{~B}$ & 0.697 & \\
\hline & & Other & $4.01 \mathrm{~A}$ & 0.744 & \\
\hline & & Total & 3.57 & 0.772 & \\
\hline & \multirow{4}{*}{ Personal sharing } & Wage & $3.59 \mathrm{C}$ & 0.803 & \multirow{4}{*}{$13.466^{* *}$} \\
\hline & & Incentive & $3.85 B$ & 0.811 & \\
\hline & & Other & $4.08 \mathrm{~A}$ & 0.748 & \\
\hline & & Total & 3.69 & 0.815 & \\
\hline
\end{tabular}

${ }^{* * *} p<0.001$; Duncan test results are A>B $>C ; M$, mean; S.D,. standard deviation.

Table 9. Differences in knowledge sharing by years of experience

\begin{tabular}{|c|c|c|c|c|c|}
\hline & Years of experience & & M & S.D. & $t$-value $(p)$ \\
\hline \multirow{24}{*}{ Knowledge sharing } & \multirow{6}{*}{ Knowledge storing } & 3 years or less & $3.16 \mathrm{~B}$ & 0.732 & \multirow{6}{*}{$24.530^{* * *}$} \\
\hline & & $4-6$ years & 3.39B & 0.700 & \\
\hline & & $7-9$ years & $3.74 \mathrm{~A}$ & 0.770 & \\
\hline & & 10-12 years & $3.82 \mathrm{~A}$ & 0.727 & \\
\hline & & 13 years or more & $3.97 \mathrm{~A}$ & 0.628 & \\
\hline & & Total & 3.34 & 0.771 & \\
\hline & \multirow{6}{*}{ Structuring sharing } & 3 years or less & $3.30 \mathrm{~B}$ & 0.771 & \multirow{6}{*}{$20.200^{* * *}$} \\
\hline & & $4-6$ years & $3.36 \mathrm{~B}$ & 0.804 & \\
\hline & & $7-9$ years & $3.94 \mathrm{~A}$ & 0.636 & \\
\hline & & $10-12$ years & $3.92 \mathrm{~A}$ & 0.741 & \\
\hline & & 13 years or more & $3.95 \mathrm{~A}$ & 0.638 & \\
\hline & & Total & 3.45 & 0.795 & \\
\hline & \multirow{6}{*}{ Relational sharing } & 3 years or less & $3.44 \mathrm{~B}$ & 0.725 & \multirow{6}{*}{$15.802^{* * *}$} \\
\hline & & $4-6$ years & $3.52 B$ & 0.829 & \\
\hline & & $7-9$ years & $3.96 \mathrm{~A}$ & 0.747 & \\
\hline & & $10-12$ years & $3.98 \mathrm{~A}$ & 0.758 & \\
\hline & & 13 years or more & $4.06 \mathrm{~A}$ & 0.615 & \\
\hline & & Total & 3.57 & 0.772 & \\
\hline & \multirow{6}{*}{ Personal sharing } & 3 years or less & 3.57B & 0.808 & \multirow{6}{*}{$12.198^{* * *}$} \\
\hline & & $4-6$ years & $3.65 \mathrm{~B}$ & 0.824 & \\
\hline & & $7-9$ years & $3.97 \mathrm{~A}$ & 0.688 & \\
\hline & & $10-12$ years & $4.17 \mathrm{~A}$ & 0.683 & \\
\hline & & 13 years or more & $4.17 \mathrm{~A}$ & 0.741 & \\
\hline & & Total & 3.69 & 0.815 & \\
\hline
\end{tabular}

${ }^{* * *} p<0.001$; Duncan test results are A>B; M, mean; S.D,. standard deviation. 
Table 10. Differences in knowledge sharing by type of organizaion

\begin{tabular}{|c|c|c|c|c|c|}
\hline & Type of organization & & M & S.D. & $F$-value $(p)$ \\
\hline \multirow{16}{*}{ Knowledge sharing } & \multirow{4}{*}{ Knowledge storing } & Franchise & 3.36 & 0.753 & \multirow{4}{*}{1.010} \\
\hline & & Private enterprise & 3.35 & 0.814 & \\
\hline & & Other & 3.14 & 0.539 & \\
\hline & & Total & 3.34 & 0.771 & \\
\hline & \multirow{4}{*}{ Structuring sharing } & Franchise & 3.50 & 0.783 & \multirow{4}{*}{2.716} \\
\hline & & Private enterprise & 3.39 & 0.820 & \\
\hline & & Other & 3.23 & 0.672 & \\
\hline & & Total & 3.45 & 0.795 & \\
\hline & \multirow{4}{*}{ Relational sharing } & Franchise & 3.57 & 0.725 & \multirow{4}{*}{1.631} \\
\hline & & Private enterprise & 3.60 & 0.836 & \\
\hline & & Other & 3.31 & 0.771 & \\
\hline & & Total & 3.57 & 0.772 & \\
\hline & \multirow{4}{*}{ Personal sharing } & Franchise & $3.76 \mathrm{~A}$ & 0.733 & \multirow{4}{*}{$4.455^{*}$} \\
\hline & & Private enterprise & $3.61 \mathrm{AB}$ & 0.919 & \\
\hline & & Other & $3.43 C$ & 0.772 & \\
\hline & & Total & 3.69 & 0.815 & \\
\hline
\end{tabular}

${ }^{*} p<0.05$; Duncan test results are A>B $>C$; M, mean; S.D.. standard deviation.

Table 11. Differences in knowledge sharing by number of employees

\begin{tabular}{|c|c|c|c|c|c|}
\hline & \multicolumn{2}{|l|}{ Number of employees } & M & S.D. & $F$-value $(p)$ \\
\hline \multirow{24}{*}{ Knowledge sharing } & \multirow{6}{*}{ Knowledge storing } & 5 persons or less & 3.38 & 0.869 & \multirow{6}{*}{0.438} \\
\hline & & 6-10 persons & 3.33 & 0.728 & \\
\hline & & 11-15 persons & 3.34 & 0.733 & \\
\hline & & 16-20 persons & 3.41 & 0.771 & \\
\hline & & 21 persons or more & 3.25 & 0.733 & \\
\hline & & Total & 3.34 & 0.771 & \\
\hline & \multirow{6}{*}{ Structuring sharing } & 5 persons or less & 3.45 & 0.867 & \multirow{6}{*}{1.202} \\
\hline & & 6-10 persons & 3.45 & 0.787 & \\
\hline & & 11-15 persons & 3.50 & 0.781 & \\
\hline & & 16-20 persons & 3.52 & 0.726 & \\
\hline & & 21 persons or more & 3.26 & 0.688 & \\
\hline & & Total & 3.45 & 0.795 & \\
\hline & \multirow{6}{*}{ Relational sharing } & 5 persons or less & $3.71 \mathrm{~A}$ & 0.856 & \multirow{6}{*}{$3.547^{* *}$} \\
\hline & & 6-10 persons & $3.56 \mathrm{AB}$ & 0.761 & \\
\hline & & 11-15 persons & $3.58 \mathrm{AB}$ & 0.666 & \\
\hline & & 16-20 persons & $3.43 \mathrm{BC}$ & 0.852 & \\
\hline & & 21 persons or more & $3.33 \mathrm{C}$ & 0.675 & \\
\hline & & Total & 3.57 & 0.772 & \\
\hline & \multirow{6}{*}{ Personal sharing } & 5 persons or less & 3.69 & 0.921 & \multirow{6}{*}{0.452} \\
\hline & & 6-10 persons & 3.68 & 0.794 & \\
\hline & & 11-15 persons & 3.74 & 0.729 & \\
\hline & & 16-20 persons & 3.72 & 0.853 & \\
\hline & & 21 persons or more & 3.59 & 0.756 & \\
\hline & & Total & 3.69 & 0.815 & \\
\hline
\end{tabular}

${ }^{* *} p<0.01$; Duncan test results are $\mathrm{A}>\mathrm{B}>\mathrm{C} ; \mathrm{M}$, mean; S.D.. standard deviation. 
의 지식공유 및 이직의도에 미치는 영향에 관한 연구에서 경영참가 는 지식공유에 정(+)의 영향력을 행사하는 것으로 나타났으며, 본 연구와 유사한 결과를 보였다.

\section{8) 회사형태에 따른 지식공유의 차이}

개인적공유 요인에서 Table 10 과 같이 통계적으로 유의미한 차 이를 보였고 $(p<0.05)$, 프랜차이즈의 평균이 기타의 평균에 비해 상 대적으로 높게 나타났다. 이는 프랜차이즈의 회사형태가 해당 업무 수행에 있어 전문성이 요구되기 때문이라 사료된다. 이러한 결과는 Park \& Chae (2018)의 주도적 성격과 지식공유 행위, 직무 특성, 조식의 인정 간 관계에 관한 연구에서 직무 복잡성과 다양성이 높 을 때가 낮을 때보다 지식공유 행위에 의해 매개된 주도적 성격과 조직 인정 간 정(+)의 관계를 조절하는 것으로 나타났으며, 본 연구 와 유사한 결과를 보였다.

9) 직원 수에 따른 지식공유의 차이

관계적공유 요인에서 Table 11 과 같이 통계적으로 유의미한 차
이를 보였고 $(p<0.01), 5$ 명이하의 평균이 21 명이상의 평균에 비해 높게 나타났다.

10) 전문분야에 따른 지식공유의 차이

구조적공유, 개인적공유 요인에서 Table 12 와 같이 통계적으로 유의미한 차이를 보였고 $(p<0.01)$, 관계적공유 요인에서 통계적으 로 유의미한 차이를 보였다 $(p<0.001)$. 구조적공유 요인은 네일아 트의 평균이 가장 높게 나타났고 피부관리의 평균이 가장 낮게 나 타났으나 던컨테스트 결과 집단으로 분류되지 않았다. 관계적공유, 개인적공유 요인은 네일아트의 평균이 피부관리의 평균에 비해 상 대적으로 높게 나타났다.

\section{Conclusion}

본 연구는 미용서비스업 종사자의 특성에 따른 지식공유의 차이 를 알아보고 향후 미용서비스업에서의 효과적인 지식공유의 방향

Table 12. Differences in knowledge sharing by beauty field

\begin{tabular}{|c|c|c|c|c|c|}
\hline & Beauty field & & $M$ & S.D. & $F$-value $(p)$ \\
\hline \multirow{24}{*}{ Knowledge sharing } & \multirow{6}{*}{ Knowledge storing } & Hair & 3.37 & 0.784 & \multirow{6}{*}{1.253} \\
\hline & & Makeup & 3.36 & 0.927 & \\
\hline & & Skin care & 3.21 & 0.665 & \\
\hline & & Nail art & 3.46 & 0.749 & \\
\hline & & Other & 3.38 & 0.830 & \\
\hline & & Total & 3.34 & 0.771 & \\
\hline & \multirow{6}{*}{ Structuring sharing } & Hair & $3.50 \mathrm{~A}$ & 0.800 & \multirow{6}{*}{$4.067^{* *}$} \\
\hline & & Makeup & $3.25 \mathrm{~A}$ & 1.019 & \\
\hline & & Skin care & $3.21 \mathrm{~A}$ & 0.696 & \\
\hline & & Nail art & $3.61 \mathrm{~A}$ & 0.647 & \\
\hline & & Others & $3.59 \mathrm{~A}$ & 0.885 & \\
\hline & & Total & 3.45 & 0.795 & \\
\hline & \multirow{6}{*}{ Relational sharing } & Hair & $3.62 B C$ & 0.778 & \multirow{6}{*}{$6.675^{* * *}$} \\
\hline & & Makeup & $3.40 B C$ & 0.817 & \\
\hline & & Skin care & $3.31 \mathrm{C}$ & 0.691 & \\
\hline & & Nail art & $3.96 \mathrm{~A}$ & 0.611 & \\
\hline & & Others & $3.75 \mathrm{AB}$ & 0.802 & \\
\hline & & Total & 3.57 & 0.772 & \\
\hline & \multirow{6}{*}{ Personal sharing } & Hair & $3.74 \mathrm{AB}$ & 0.819 & \multirow{6}{*}{$3.439^{* *}$} \\
\hline & & Makeup & $3.64 \mathrm{AB}$ & 0.963 & \\
\hline & & Skin care & $3.46 \mathrm{~B}$ & 0.765 & \\
\hline & & Nail art & $3.90 \mathrm{~A}$ & 0.790 & \\
\hline & & Others & $3.62 A B$ & 0.661 & \\
\hline & & Total & 3.69 & 0.815 & \\
\hline
\end{tabular}

${ }^{* *} p<0.01$; ${ }^{* * *} p<0.001$; Duncan test results are A>B $>C$; M, mean; S.D., standard deviation. 
을 제시하는데 목적이 있다. 연구의 목적을 바탕으로 한 결론은 다 음과 같다.

첫째, 조사대상의 일반적 특성을 알아본 결과, 성별은 여자, 연령 은 20 대, 결혼여부는 미혼, 학력은 대학교 재학/졸업, 직급은 인턴 (어시스트), 급여형태는 급여, 미용경력은 3년 이하, 회사형태는 프 랜차이즈, 직원 수는 6-10명, 미용분야는 헤어가 가장 높게 나타 났다.

둘째, 지식공유의 타당도 및 신뢰도를 알아본 결과, 지식저장, 구 조적공유, 관계적공유, 개인적공유의 네 개의 요인으로 도출되었 다.

셋째, 미용서비스업 종사자의 특성에 따른 지식공유의 차이를 알 아본 결과, 지식공유는 성별, 연령, 결혼여부, 학력, 직급, 급여형 태, 근무경력, 회사형태, 직원 수, 전문분야에 따라 유의미한 차이 가 있는 것으로 나타났다. 연령에서 개인적공유는 50 대의 평균이 20대의 평균에 비해 상대적으로 높게 나타났으며, 직급에서 지식저 장, 구조적공유, 관계적공유, 개인적공유 네 요인 모두 원장(대표) 의 평균이 인턴(어시스트)의 평균에 비해 상대적으로 높게 나타났 다. 이는 연령이 높아질수록 많은 정보들을 얻게 되고 그만큼 많은 지식이 쌓이는 것으로 보여지며. 상대적으로 처음 미용을 시작하는 인턴(어시스트)는 이러한 원장(대표)의 도움을 많이 받는다는 것을 알 수 있다. 이는 미용서비스업을 처음 시작하는 단계의 종사자들 의 지식공유도 더욱 활발히 이루어져야 할 것으로 판단된다.

미용서비스업의 종사자들은 더욱 많은 지식공유를 함으로 인하 여 이것은 개인의 발전과 더불어 조직의 발전으로 이어질 수 있을 것이라 사료된다.

\section{Author's contribution}

JEP did research design, data collection and analysis, and overall papers, and BUJ helped. EJP was the general manager of the paper.

\section{Author details}

Jung-Eun Park (Professor), Department of Hair and Makeup Design, Seokyeong University, 124 Seokyeongro, Sungbuk-gu, Seoul 02713, Korea; Byung-Un Jin (Professor), Design \& Art Institute, Hansung University, Samseongyo-ro 16-gil, Seongbuk-gu, Seoul 2876, Korea; Eun-Jun Park (Professor), Department of Hair and Makeup Design, Seokyeong University, 124 Seokyeong-ro, Sungbuk-gu, Seoul 02713, Korea.

\section{References}

Bae SH, Baek SI. Exploring impact of individual network position toward knowledge sharing intention. The Journal of Society for e-Business Studies, 21: 29-50, 2016.

Cho KJ, Kang SD. The effect of management participation on knowledge sharing and turnover intention of workers. Korean Journal of Industrial Relations, 27: 1-28, 2017.

Choi SH, Chung TW. The relationship among the local sports council members proactive personality, openness to diversity, knowledge sharing, and innovation behavior. The Korean Society of Sports Science, 27: 753-765, 2018.

Chung DS. The Influence of the knowledge sharing and its antecedent factors on the innovative behavior. Journal of the Korean Data Analysis Society, 8: 2063-2080, 2006.

Grant RM. Toward a knowledge-based theory of the firm. Strategic Management Journal, 17: 109-122, 1996.

Jeon YR, Hong AR. The effect of knowledge sharing activity of SMEs on corporate performance: focused on mediating effect of acceptance intention and knowledge management system. Innovation Studies, 14: 1-25, 2019.

Kang YJ. The impact of knowledge sharing on work performance: an empirical analysis of the public employees' perceptions in Korea. Korean Public Administration Quarterly, 17: 431-458, 2005.

Kim TY, Lee SN. The mediating effect of job satisfaction on the relationship between internal marketing and the customer orientation of employees in the beauty service industry. Asian Journal of Beauty and Cosmetology, 16: 555-567, 2018.

Kim JE, Joh GS. A study on knowledge sharing of secretaries. Journal of Secretarial Studies, 13: 23-44, 2004.

Kim SS, Kim YW. An empirical study on the key success factors of knowledge management. Korean Management Review, 29: 585-616, 2000.

Lee $\mathrm{HJ}$, Cha YJ. A study on the knowledge sharing and work performance: with focus on the center government. Korean Public Administration Quarterly, 18: 515-538, 2006.

Lee WH, Moon JY. A study on the effect of knowledge sharing 
and utilization on field project performance. Journal of the Korea society of computer and information, 23: 151156, 2018.

Lee YJ, Lee JC, Lim JK. The effects of beauty service industry employees' job satisfaction on perception of service quality by customers. Asian Journal of Beauty and Cosmetology, 10: 79-90, 2012.

Min IS, Park JH, Lim JH, Park EJ. How to uniform satisfaction affected by uniform recognition in the beauty services workers. Asian Journal of Beauty and Cosmetology, 11: 289-296, 2013.

Kim DW. Analysis on the relationship between organization citizenship behaviors and local government employees's intention for knowledge sharing. The Journal of Busan Studies, 9: 33-57, 2011.
Nonaka I. A dynamic theory of organizational knowledge creation. Organization Science, 5: 14-37, 1994.

Park JS, Chae HS. Proactive personality, knowledge sharing behavior, job characteristics, and organizational recognition: an application of costly signaling theory. Journal of Korea Academia-Industrial cooperation Society, 19: 128-137, 2018.

Song JS. The effect of shared leadership on organizational trust, knowledge sharing and innovative behavior. The Journal of the Korea Contents Association, 19: 485-500, 2019.

Seol HD. Transformational leadership, social capital, and knowledge sharing. The Korean-Japanese Journal of Economics and Management Studies, 62: 45-69, 2014. 


\section{국문초록}

\section{미용서비스업 종사자의 특성에 따른 지식공유}

박정은 ${ }^{1}$, 진병운 ${ }^{2}$, 박은준 $^{1 *}$

${ }^{1}$ 서경대학교 헤어·메이크업디자인학과, 서울, 한국

${ }^{2}$ 한성대학교 디자인아트평생교육원, 서울, 한국

목적: 본 연구는 미용서비스업 종사자의 일반적 특성에 따른 지식공유를 연구하여 미용산업에서의 효과적인 지식공유의 방향을 제 시하고자 한다. 방법: 미용서비스업 종사자를 대상으로 자료를 수집하였고, Statistical Package for the Social Sciences (SPSS) 22.0 을 이용하여 분석하였다. 분석방법은 빈도분석, 요인분석, 신뢰도분석, 독립표본 $t$-test, 일원변량분석(one way ANOVA)을 하였다. 결과: 지식공유는 성별, 연령, 결혼여부, 학력, 직급, 급여형태, 근무경력, 회사형태, 직원 수, 전문분야에 따라 유의미한 차이가 있 는 것으로 나타났다. 결론: 본 연구결과가 미용서비스업의 발전을 위한 기초자료로 활용되기를 바라며, 미용서비스업의 종사자들 은 더욱 많은 지식공유를 함으로 인하여 개인의 발전과 더불어 조직의 발전으로 이어질 수 있을 것이라 사료된다.

핵심어: 미용, 미용산업, 미용서비스업 종사자, 지식공유, 일반적 특성

\section{참고문헌}

강여진. 지식공유 영향요인이 업무성과에 미치는 영향: 중앙부처공무원의 인식을 중심으로. 한국행정논집, 17: 431-458, 2005.

김대원. 지방정부 관료들의 지식공유 의도 영향 요인 분석: 부산 경남지역 관료들의 지식공유 의도에 대한 조직시민행동의 영향 분석을 중심으로. 부산연구, 9: 33-57, 2011.

김상수, 김용우. 지식경영의 성공요인에 관한 실증적 연구. 경영학연구, 29: 585-616.

김정은, 조계숙. 비서직 종사자의 지식공유에 관한 연구. 비서·사무경영연구, 13: 23-44, 2004.

김태열, 이성내. 뷰티서비스업 구성원의 내부마케팅과 고객지향성의 관계에서 직무만족의 매개효과. 아시안뷰티화장품학 술지, 16: 555-567, 2018.

민인숙, 박재홍, 임지현, 박은준. 미용서비스 종사자의 유니폼 인식이 유니폼 개선사항에 미치는 영향. 아시안뷰티화장품 학술지, 11: 289-296, 2013.

박지성, 채희선. 주도적 성격과 지식 공유행위, 직무 특성, 그리고 조직의 인정 간 관계에 관한 연구: 비싼 신호보내기 이 론을 중심으로. 한국산학기술학회논문지, 19: 128-137, 2018.

배순한, 백승익. 개인의 네트워크 위치가 지식공유 의도에 미치는 영향에 관한 탐색적 연구. 한국전자거래학회지, 21 : 29-50, 2016.

설현도. 변혁적 리더십이 사회적 자본과 지식 공유에 미치는 영향. 한일경상논집, $62: 45-69,2014$.

송정수. 공유리더십이 조직신뢰, 지식공유 및 혁신행동에 미치는 영향. 한국콘텐츠학회지, 19: 485-500, 2019.

이영주, 이재철, 임재국. 미용서비스산업 종사자들의 직무만족이 고객의 서비스품질 지각에 미치는 영향. 아시안뷰티화장

품학술지, 10: 79-90, 2012.

이원희, 문재영. 지식공유 및 활용이 현장프로젝트 성과에 미치는 영향에 관한 연구. 한국컴퓨터정보학회지, 23: 151156, 2018.

이홍재, 차용진. 지식공유와 업무성과에 관한 실증연구: 중앙행정기관을 중심으로. 한국행정논집, 18: 515-539, 2006.

전유리, 홍아름. 중소기업의 지식공유 활동이 기업성과에 미치는 영향: 지식경영시스템 수용 의도 매개 효과를 중심으로. 한국혁신학회지, 14: 1-25, 2019. 
Effective knowledge sharing in the beauty industry

정동섭. 지식공유의 선행요인과 지식공유가 혁신행동에 미치는 영향. 한국자료분석학회지, 8: 2063-2080, 2006.

조규준, 강수돌. 경영참가가 구성원들의 지식공유 및 이직의도에 미치는 영향: 조직 공정성의 매개효과. 산업관계연구, 27: 1-28, 2017.

최순혁, 정태욱. 시 도체육회 직원의 주도적 성격, 다양성 수용도, 지식공유, 그리고 혁신행동 간의 관계. 한국체육과학회 지, 27: 753-765, 2018. 


\section{中文摘要}

\section{基于共性和组织特征的美容行业员工知识共享}

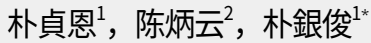

1首尔大学生活科学研究所, 首尔, 韩国

汉城大学设计与艺术, 首尔, 韩国

目的：根据个人组织特征，建立美容行业服务工作之间有效知识共享的方向。方法：采用社会科学统计软件包 （SPSS）22.0对美容服务行业从业人员进行统计分析。数据分析利用频数分析、因子分析、信度分析、独立 样本t检验、单因素方差分析。结果: 不同性别、年龄、婚姻状况、学历、职位、工资类型、工作经历、组织类 型、组织内员工数量、专业领域的员工在知识共享方面存在显著差异。结论: 本研究所获得的基础数据可用于美 容行业的发展, 为美容行业的组织和整个行业提供知识共享的途径。

关键词：美容，美容行业，美容行业员工，知识共享，共性 
